Laboratorio de Arte,3-1990 http://dx.doi.org/10.12795/LA.1990.i03.18

\title{
PEDRO DE CAMPOLARGO, PINTOR FLAMENCO
}

\author{
por Fernando Quiles Garcta
}

La presencia de artistas flamencos en Sevilla es constatable desde el ocaso de la Edad Media. Resultaría prolijo e inútil recordar todos sus nombres. Algunos de ellos, incluso, jugaron un papel destacadísimo en la configuración de los distintos estilos artísticos en nuestra ciudad; ese es el caso, por ejemplo, de José de Arce, considerado habitualmente como el introductor de estética berninesca en la escultura hispalense. Tan sugerente como esta aportación fue la de los pintores, a quienes habría que situar en el origen de una serie de novedades formales, una de las cuales vamos a considerar en el presente estudio.

Pintores flamencos fueron Cornelio Schut, Pedro de Campolargo, Juan van Mol o Sebastián Faix. Todos ellos estaban ya establecidos en Sevilla a mediados del XVII. Por el carácter de sus realizaciones, indudablemente, gozaron de un gran éxito entre la clientela del momento. Y sin embargo, muy pocas obras han llegado hasta nosotros, si acaso algo de Schut o de Campolargo, pues del resto nada más que hay testimonios escritos.

De Pedro de Campolargo queremos hacer una breve semblanza, aprovechando el estudio de un grabado hasta ahora inédito. Son muy escasas las noticias que se pueden reunir sobre su estancia en nuestra ciudad, y todas ellas de un período de años que va desde 1640 a $1687^{1}$. La primera fecha es la del bautismo de un hijo que tuvo con Ángela Adriaensens, su esposa ${ }^{2}$. El recién nacido fue inscrito en la iglesia del Sagrario de la Catedral hispalense el 17 de noviembre de 1640. Entre esta parroquia y la de la Magdalena se desarrolló

1. La mayor parte de los datos biográficos de Campolargo referidos en este trabajo los dio a conocer Duncan T. KINKEAD: Pintores flamencos en ls Sevilla de Murillo, en “Archivo Hispalense", n. ${ }^{\circ} 195$ (Sevilla, 1982), pág. 52.

2. Desde luego el apellido Adriaensens es un claro indicio del origen de su esposa, con la que debió contraer matrimonio antes de abandonar su país. Es indudable que Campolargo adquirió el título de maestro en su país. 
la vida de Campolargo, si bien los últimos días los pasó en la de San Nicolás, donde fue finalmente enterrado el 23 de enero de $1687^{3}$. De su vida profesional se sabe poca cosa, tan sólo que asistió a la Academia sevillana en 1660, y que ejerció de maestro de Bartolomé Díaz a partir de ese año ${ }^{4}$.

También es muy breve el comentario que cabe hacer de su obra. Fue colaborador de un desconocido pintor sevillano llamado Pedro Rodríguez, a quien le grabó algunos dibujos ${ }^{5}$. Este hecho coincide con las referencias biográficas de historiadores de fines del siglo pasado o principios de éste. En ellas se pone de manifiesto la ocupación del artífice en géneros menores de la pintura. Por ejemplo, Ceán resalta su dedicación al paisaje ${ }^{6}$, en tanto que Nagler nos lo muestra no sólo como paisajista, sino también como retratista y decorador de tramoyas ${ }^{7}$. En definitiva, tareas habituales en un pintor flamenco.

Queremos participar, en cierta medida, en la recomposición del perfil artístico de este autor, con el estudio de un grabado realizado en 1653 para el frontispicio del folleto titulado: "Forma del voto y iuramento que la imperial hermandad de la Pura y Limpia Concepción de la Virgen Señora, concebida sin mancha de pecado original, haze a quatro de iuli, dia del Señor San Laureano, deste presente año de 1653, en el convento de Regina Angelorum de Sevilla". El impreso que sirve de soporte al dibujo objeto de nuestra atención no es más que un alegato inmaculadista, realizado precisamente por aquéllos que pusieron en duda la pureza de María, promoviendo, por lo tanto, un conflicto de gran magnitud en el seno de la sociedad sevillana ${ }^{8}$.

El grabado, firmado por " $P^{o}$ de Campolargo ex." 9 , confirma la procedencia del autor, y nos sirve para establecer un nexo entre Sevilla y Flandes. Representa a la Inmaculada Concepción, según la visión apocalíptica, y aureolada por un ramillete de flores y frutas. Este nimbo vegetal, como veremos, es la evidencia más clara del acervo flamenco del pintor.

La Virgen Inmaculada se muestra en su forma habitual, de pie, vestida con túnica y manto, dispuesta frontalmente, aunque efectuando con el rostro un ligero giro hacia su derecha; lleva las manos colocadas a la altura del pecho,

3. Duncan T. KINKEAD: Pintores..., o. c., pág. 52.

4. Duncan T. KINKEAD: Pintores..., o. c., pág. 52.

5. Las láminas que justifican este aserto se encuentran en: Elena PÁEZ RIOS: Repertorio de grabados españoles en la Biblioteca Nacional, III (Madrid, 1983), pp. 47-48.

6. Juan Agustín CEAN BERMÚDEZ: Diccionario histórico de los más ilustres profesores de las Bellas Artes en España (Madrid, 1800), t. I, pág. 206.

7. G. K. NAGLER: Allgemeines Künstler-Lexicon (Linz, 1904), II, pág. 387. Citado por Duncan T. KINKEAD: Pintores... o. c., pág. 53.

8. Aunque no es este el lugar para ocuparnos del suceso, refirámoslo siquiere brevemente. La chispa que provocó la crisis saltó en septiembre de 1613, cuando fray Diego de Molina, religioso del convento de Regina, en un sermón hizo algunos comentarios atentatorios contra la virginidad de María. Desde ese instante se produjo una revuelta antidominica, en cierto modo dirigida por los franciscanos y jesuítas. Por ello resulta muy interesante esta publicación de 1653. V. Jesús M. PALOMERO PÁRAMO: Ciudad de retablos (Sevilla, 1987), pp. 41-43.

9. Se encuentra en el Archivo Histórico Municipal de Sevilla, sección 11, t. XVI, legajos en folio, cuaderno n. 26. 
unidas en un gesto orante. A los pies se sitúa la luna, con las puntas hacia arriba. Esta Inmaculada posee algunos atisbos de originalidad: el cabello, por ejemplo, resulta inusual por lo largo y suelto, con onduladas y larguísimas guedejas de puntas abiertas, siguiendo modelos probablemente flamencos. La túnica, por otro lado, es de mangas ajustada a semejanza de las Inmaculadas de Cornelio Schut) y de pliegues paralelos y muy reducidos, excepto en el extremo inferior. Esta prenda, en cierto modo, recuerda por su simpleza a la de la Inmaculada Concepción de Ignacio de Ríes ${ }^{10}$. El manto es de mayor riqueza plástica y dinamismo. En conjunto la plasmación de la imagen de María todavía obedece a los cánones previos a la renovación murillesca. Recordemos que Murillo sólo realizará sus Inmaculadas arquetípicas a partir de la década de los sesenta.

La guirnalda sirviendo de marco a una figura, repetimos, es de tradición flamenca. Concretamente debió de crearse en Amberes ${ }^{11}$, dado que en esta ciudad trabajaron los maestros que se ocuparon de ella hasta la saciedad. El primero en introducirla en su pintura fue Jan Bruegel I, o de Velours (15681625), uno de los hijos de Pieter Bruegel el Viejo. Si bien fueron sus sucesores quienes la transformaron en un auténtico género pictórico. Por ejemplo, Frans Snyders (1579-1657), discípulo de su hermano Pieter, y colaborador suyo. Pero hemos de valorar la figura de Daniel Seghers (1590-1661) como la del propagador de estos desarrollos florales. Con este pintor trabajó Cornelis Schut, tío del artista sevillano del mismo nombre.

La guirnalda alcanzó un gran éxito a lo largo de la segunda mitad del XVII, no sólo en Flandes, sino en otros países europeos. He ahí cómo Hans von Haachen, pintor germano, recogió el tema en La Virgen y el Niño de la iglesia de Santiago, en Praga ${ }^{12}$.

De modo que nació en Amberes y se extendió por Europa Central. Habría que considerar el influjo de los manieristas holandeses a la hora de pensar en su invención. Recordemos, sobre todo, a Georg Hoefnagel o a Nicolaes de Bruyn, pues, guiados por su afán naturalista, grabaron multitud de estampas de plantas y animales con un carácter puramente científico.

También llegó esta moda a España. La interpretó Juan de Arellano en un cuadro hecho en colaboración con Francisco Camilo ${ }^{13}$. Del mismo modo que Andrés Pérez en la obra Guirnalda de flores con San Joaquín, Santa Ana y la Virgen niña del museo de Córdoba; y no fue un trabajo aislado, pues de similar

10. Reproducida por Enrique VALDIVIESO: Historia de la pintura sevillana (Sevilla, 1986), pág. 191.

11. Duncan T. KINKEAD: (Pinıores..., o. c., pág. 52), menciona una declaración en la cual Campolargo consta como oriundo de Amberes.

12. V. Jaromir NEUMANN: Die rudolfinische Kunst und Niederlanden, en "Netherlandish Mannerism" -actas del simposio celebrado en 1984 en Estocolmo- (Estocolmo, 1985), pág. 56.

13. V. Enrique VALDIVIESO: Una vánitas de Arellano y Camilo, "Boletín del Seminario de Arte y Arqueología", t. XIV (Valladolid, 1979), pp. 479-482. Fue dada a conocer mientras perteneció a la colección de don Carlos Medina, de Sevilla. Nos ha comunicado el profesor Valdivieso que, en la actualidad, el cuadro ya no se encuentra en dicho paradero. 
estilo en el Niño Jesús, de una colección sevillana ${ }^{14}$. Cabría situar a Pedro de Campolargo en la raíz del uso de la guirnalda en Sevilla. El grabado que presentamos prueba este extremo. O quizá podría pensarse en Cornelio Schut, pues debió tener referencias de la guirnalda por su tío y maestro.

La cenefa de flores de Campolargo se encuentra muy próxima a los dibujos de los naturalistas holandeses referidos, claro está que no llega a alcanzar ni su preciosismo ni su grado de fidelidad al natural. Así la libélula colocada en el ángulo superior izquierdo recuerda a algunas de las que Hoefnagel dibujara hacia 1591, con un vamor naturalista, aunque en este caso no se aprecia bien por el carácter de marginal y anecdótico. De otra parte, la cartela situada a los pies de la Virgen proclama la tradición manierista ${ }^{15}$.

Hasta tanto no se conozca un mayor número de obras será difícil juzgar el estilo de Campolargo, y menos aún si seguimos careciendo de trabajos al óleo. Tan sólo avanzar que en 1653 era innegable el influjo flamenco.

14. V. Enrique VALDIVIESO: Historia..., o. c., págs. 298-299, ilustración 247.

15. Algunas de ellas están reproducidas por Ingvar BERGSTRÖM: On Georg Hoefnagel's manner of working with notes on the influence of the Archetypa series of 1592, en "Netherlandish...", pp. 176-187. 


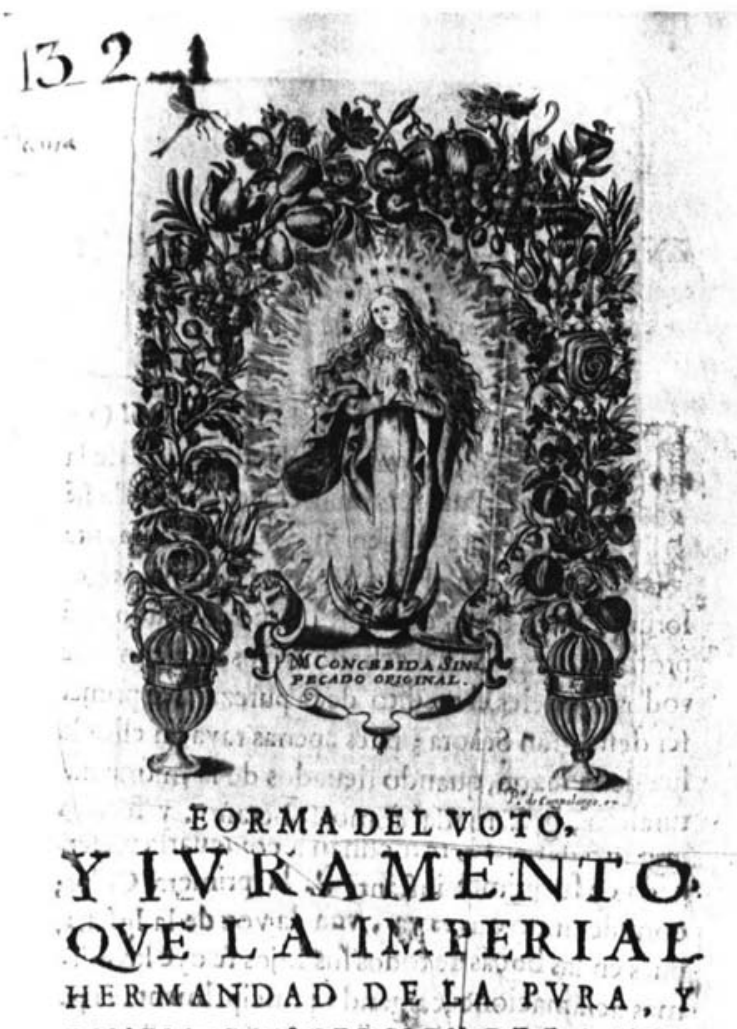

IIM P A CONCEPCIOY DE LA VIRUEN NISEN̈'ORA, CONCEBILA SIN MANCHA DE PEC Kं OKIGINAL, HAZEA QVATRQ Inmaculada Concepción rodeada de una guirnalda. Obra de Pedro de Campolargo (1653). 